\title{
Effect of Somatostatin and Calcium Deprivation on Cholecystokinin or Caerulein-Induced Insulin and Glucagon Release from the Isolated Perfused Rat Pancreas

\author{
Makoto OTSUKI, Choitsu SAKAMOTO, Hosai YUN, \\ Mitsuo MAEDA, Soichiro MORITA \\ AND SHIGEAKI BABA
} \\ The Second Department of Internal Medicine, Kobe University \\ School of Medicine, Kusunoki-cho, Ikuta-ku, Kobe 650, Japan
}

\begin{abstract}
Synopsis
The present experiments were undertaken to investigate the effect of alteration in on extracellular calcium concentration and of somatostatin on cholecystokinin(CCK)- and caerulein-induced insulin and glucagon release from the isolated perfused rat pancreas. In control studies using perfusate containing $2.5 \mathrm{mM} \mathrm{CaCl}_{2}$ and $50 \mathrm{mg} / \mathrm{d} l$ glucose, CCK and caerulein caused insulin and glucagon release in a dose-related fashion. During perfusion with calcium free medium, insulin release was markedly inhibited. Subsequent introduction of $2.5 \mathrm{mM} \mathrm{CaCl}_{2}$ to the medium restored insulin response toward control levels. Extracellular calcium depletion, however, had no effect on CCK- or caerulein-induced glucagon release. The output of glucagon in the absence of calcium was comparable to that seen in the control experiments. On the other hand, somatostatin abolished the increase in glucagon secretion, but not the increase in insulin secretion, when perfused simultaneously with CCK or caerulein. However, pretreatment for $10 \mathrm{~min}$ with somatostatin blocked even insulin secretion. The effects of somatostatin on hormonal discharge are suggested to be related to an alteration in the handling of or response to calcium. Recently, somatostatin has also been shown to inhibit calcium uptake by islets. Thus, the present results indicate a differential sensitivity of CCK- and caerulein-stimulated alpha and beta cell to extracellular calcium depletion and to the effect of somatostatin.
\end{abstract}

Cholecystokinin (CCK) is an established stimulator of exocrine pancreatic function (Harper and Raper, 1943 ; Ivy and Oldberg, 1928) and has been reported by some to also stimulate insulin and glucagon release (Buchanan et al., 1968 ; Dupre et al., 1969; Iversen, 1971 ; Made et al., 1967; Otsuki et al., 1979; Unger et al., 1967). Calcium is known to play an important role in the secretory process of exocrine and endocrin tissues (Rubin, 1970). Although the effects of calcium on CCK-stimulated pancreatic exocrine function (Gardner et al., 1975; Kanno and Nishimura, 1976; Kanno and Yamamoto, 1977) and on arginine induced insulin and glucagon release (Curry et al.,
1968; Gerich et al., 1974; Grodsky and Bennett, 1966 ; Leclercq-Meyer et al., 1973 ; $1976,1978,1979)$ has been widely studied, little is known of the effect of this cation on CCK-stimulated insulin and glucagon release.

In the present study we investigated whether the process of CCK-induced insulin and glucagon release relies on the presence of extracellular and inwardly transported calcium, like arginine-induced responses which are well known to require both the presence of extracellular calcium and the inward transport of this cation exert its insulinotropic and glucagonotropic effect The studies were performed using the in vitro 
perfused rat pancreas preparation submitted to calcium deprivation. In addition, the effect of somatostatin, revealed to inhibit calcium uptake of islets (Bhathena et al., 1976; Fujimoto and Ensinck, 1976), on the insulin and glucagon response to CCK was investigated.

In the present study, not only highly purified natural porcine CCK but also synthetic caerulein were used as stimulating agents. Because it has been reported that pure natural porcine CCK obtainable from G.I.H. Laboratories in Stockholm contains $1-2 \%$ gastric inhibitory polypeptide (GIP) by weight (Ipp et al., 1977), which is found to stimulate insulin and glucagon release (Dupre et al., 1973; Pederson and Brown, 1976, 1978 ; Ravinovitch and Dupre, 1974). The chmical structure of caerulein shows a marked resemblance to that of certain gastrointestinal hormones and the $\mathrm{COOH}$ terminal pentapeptide of caerulein is identical with that of mammalian CCK. The molecule also has a sulphated tryptophan residue at position seven from the $\mathrm{COOH}$ terminus, and it contains no contaminating peptides. Moreover, it has been proven that the biological action of the peptide closely resembles that of porcine CCK (Bertaccini et al., 1968, 1969).

\section{Materials and Methods}

Panreases from male wirats fed ad libitum, weighing $250-280 \mathrm{~g}$, were isolated and perfused by the technique of Kanno et al. (1976). The basic medium had the following composition: $\mathrm{NaCl} 118.5$ $\mathrm{mM} ; \mathrm{KCl} 4.7 \mathrm{mM} ; \mathrm{CaCl}_{2} 2.5 \mathrm{mM} ; \mathrm{KH}_{2} \mathrm{PO}_{4} 1.2 \mathrm{mM}$; and $\mathrm{NaHCO}_{3} 25 \mathrm{~mm}$. In the calcium free medium, $\mathrm{CaCl}_{2}$ was replaced by $\mathrm{NaCl}$ to make the perfusion medium isotonic. The perfusate also contained $2.5 \%$ bovine serum albumin (BSA: fraction V, Armour Pharmaceutical Co., Phoenix, Ariz.), $4.6 \%$ dextran T-70 (Pharmacia Fine Chemicals, Uppsala, Sweden), $50 \mathrm{mg} / \mathrm{d} l$ glucose and, as required, $10 \mathrm{ng} / \mathrm{ml}$ somatostatin (SRIF: cyclic somatostatin, Protein Research Foundation, Osaka, Japan). The perfusate was equilibrated against a mixture of oxygen and carbon dioxide $(95: 5)$, with a resultant $\mathrm{pH}$ of 7.4 , and it entered the pancreas through the celiac and superior mesenteric arteries at a temperature of $37^{\circ} \mathrm{C}$ via a nonrecirculating open circuit. The flow rate was set around $2 \mathrm{ml}$ per min. The pancreas was perfused for an equilibration period of at least $40 \mathrm{~min}$ before samples were measured for their hormone content. Samples of the portal effluent were collected at onemin intervals in chilled tubes for measurement of insulin and glucagon concentrations.

Pure natural porcine CCK ( $1 \mathrm{mg}$ : $3,500 \mathrm{U}$, GastroIntestinal Hormone[G.I.H.] Research Units, Karolinska Institute, Stockholm, Sweden) or synthetic caerulein (Kyowa Hakko Kogyo, Ltd., Tokyo, Japan) was applied by changing the medium reservoir.

Immunoreactive insulin(IRI) was measured by polyethylene glycol radioimmunoassay (Desbuquois and Aurbach, 1971). Immunoreactive glucagon(IRG) was determined by radioimmunoassay with a talc absorption technique (Aguilar-Parada et al., 1969) with antiserum $30 \mathrm{~K}$ (purchased from the University of Texas Southwestern Medical School, Dallas, Tex.). Rat insulin and porcine glucagon were used as standards in IRI and IRG assay, respectively.

\section{Results}

The Effect of CCK and Caerulein on Insulin and Glucagon Release

When the effect of CCK and caerulein on endocrine pancreas was studied, a 20min basal period was followed by a 20 -min stimulatory period and then a 20 -min recovery period. The IRI and IRG response to CCK and caerulein was over in $5 \mathrm{~min}$ despite the continued infusion of the peptides for $20 \mathrm{~min}$. With CCK or caerulein, the time course of secretion of IRI preceded that of IRG. The maximal level in IRI was attained within the first min after the perfusion of the secretagogue was started, while that in IRG was attalned in at the second min (Fig. 1, 2).

The threshold concentration for the stimulatory action of CCK lies between 10 and $50 \mathrm{mU} / \mathrm{m} l$, while that of caerulein capable of producing and appreciable increase of IRI and IRG release was $1.0 \mathrm{ng} /$ $\mathrm{m} l$. The peak values of IRI and IRG in response to $1 \mathrm{ng} / \mathrm{m} l$ caerulein were $1.2 \pm 0.3$ $\mathrm{ng} / \mathrm{m} l$ and $134 \pm 15 \mathrm{pg} / \mathrm{m} l$, in constrast with the control $0.6 \pm 0.1 \mathrm{ng} / \mathrm{m} l$ and $74 \pm 9.0 \mathrm{pg} / \mathrm{m} l$ 


\section{CCK $(100 \mathrm{mU} / \mathrm{ml})$}
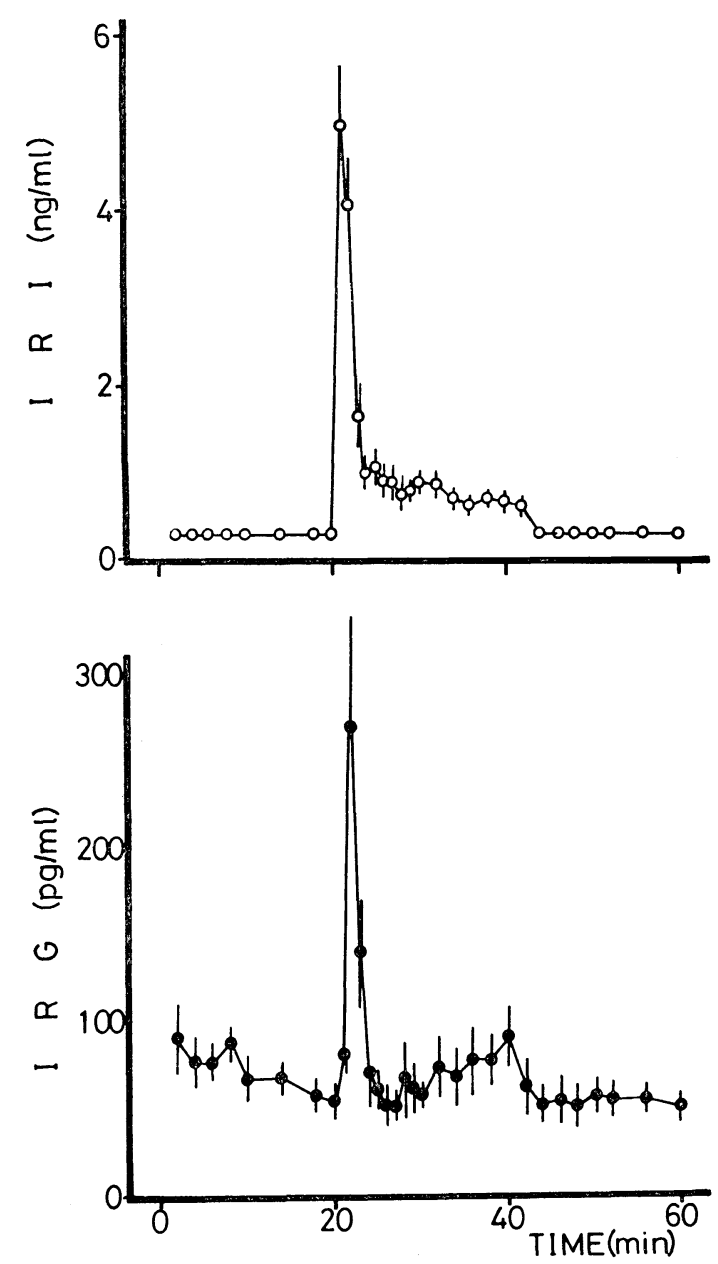

Fig. 1. Effect of $100 \mathrm{mU} / \mathrm{ml}$ cholecystokinin(CCK) on immunoreactive insulin(IRI) and immunoreactive glucagon(IRG) release in the pancreatic effluent. Results are expressed as mean \pm SEM of 10 experiments.

( $\mathrm{p}<0.05$, respectively). The dose-action relationship for CCK-and caerulein-induced IRI and IRG release is illustrated in Fig. 3 , which refers to the maximal concentration of IRI during $20 \mathrm{~min}$ exposure to various concentration of stimulating agenıs. The endocrine responses were transitory and
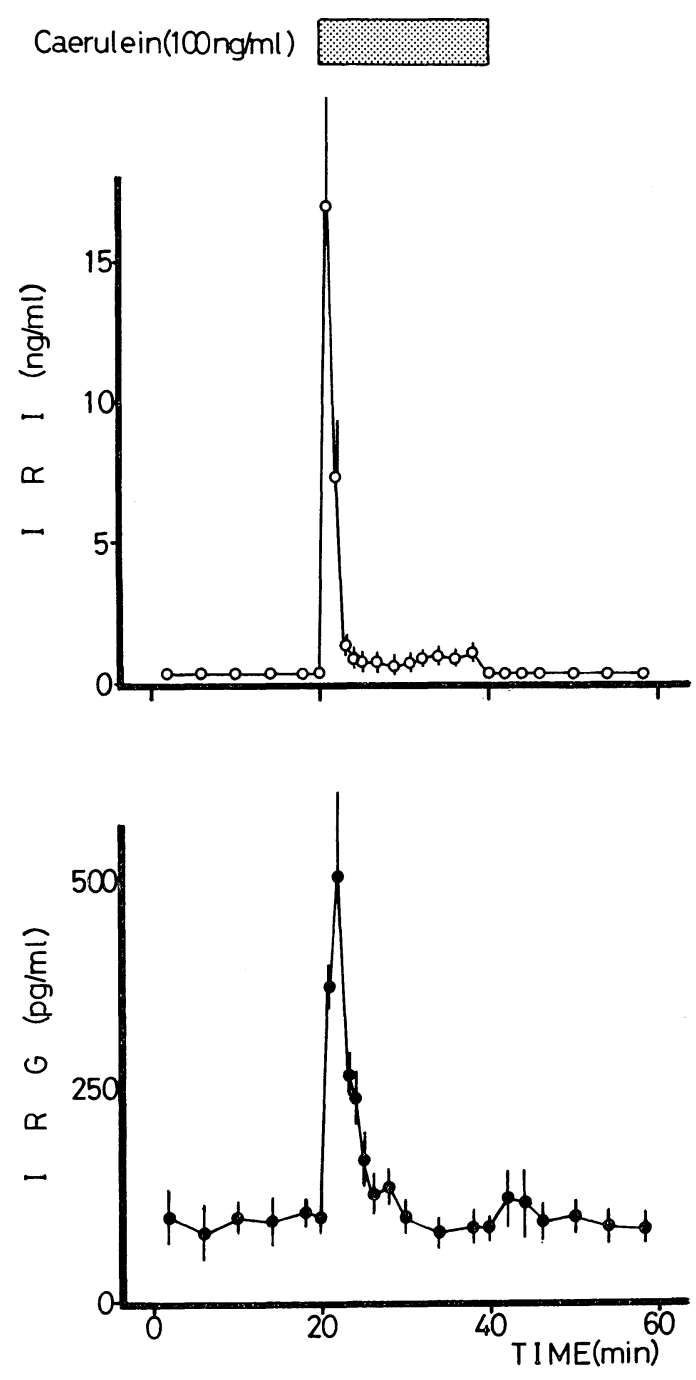

Fig. 2. Effect of $100 \mathrm{ng} / \mathrm{ml}$ caerulein on IRI and IRG release in the pancreatic effluent. Results are expressed as mean \pm SEM of 8 experiments.

proportional to the doses up to $100 \mathrm{mU} / \mathrm{m} l$ CCK (Fig. 3, upper panel). A further increase in the concentration of $\mathrm{CCK}$ resulted in a decreasing response of IRG release. The peak values of IRI and IRG in response to $100 \mathrm{mU} / \mathrm{m} l \mathrm{CCK}$ were $6.8 \pm 0.3 \mathrm{ng} / \mathrm{m} l$ and $270.0 \pm 73.8 \mathrm{pg} / \mathrm{m} l$, respectively, while those 


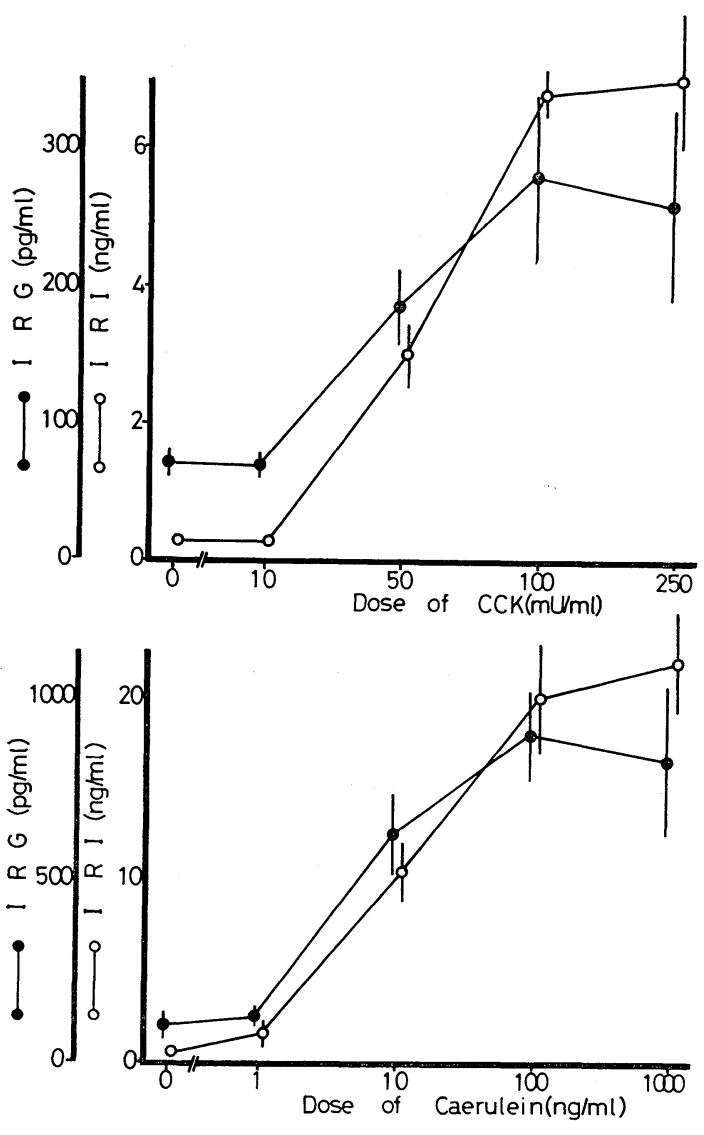

Fig. 3. Relationship between concentration of CCK(upper panel) or caerulein (lower panel) and the maximal IRI and IRG concentration in the pancreatic effluent. Results are expressed as mean \pm SEM of 8 to 10 experiments.

in response to $250 \mathrm{mU} / \mathrm{ml} \mathrm{CCK}$ were $7.1 \pm$ $1.2 \mathrm{ng} / \mathrm{m} l \quad \mathrm{CCK}$ were $7.1 \pm 1.2 \mathrm{ng} / \mathrm{m} l$ and $260.0 \pm 70.0 \mathrm{pg} / \mathrm{m} l$. Similar relationships were observed between the doses of caerulein and the peak values for IRI and IRG concentrations in the portal effiuent (Fig. 3, lower panel). A maximal response in endocrine pancreas was obtained with 100 $\mathrm{ng} / \mathrm{m} l$ caerulein. A further increase in the perfused concentration was followed by a lower rate of release of the IRG $(100 \mathrm{ng} / \mathrm{m} l$ caerulein : $897.8 \pm 138.7 \mathrm{pg} / \mathrm{m} l, 1,000 \mathrm{ng} / \mathrm{m} l$ caerulein : $821.6 \pm 197.2 \mathrm{pg} / \mathrm{ml}$ ).

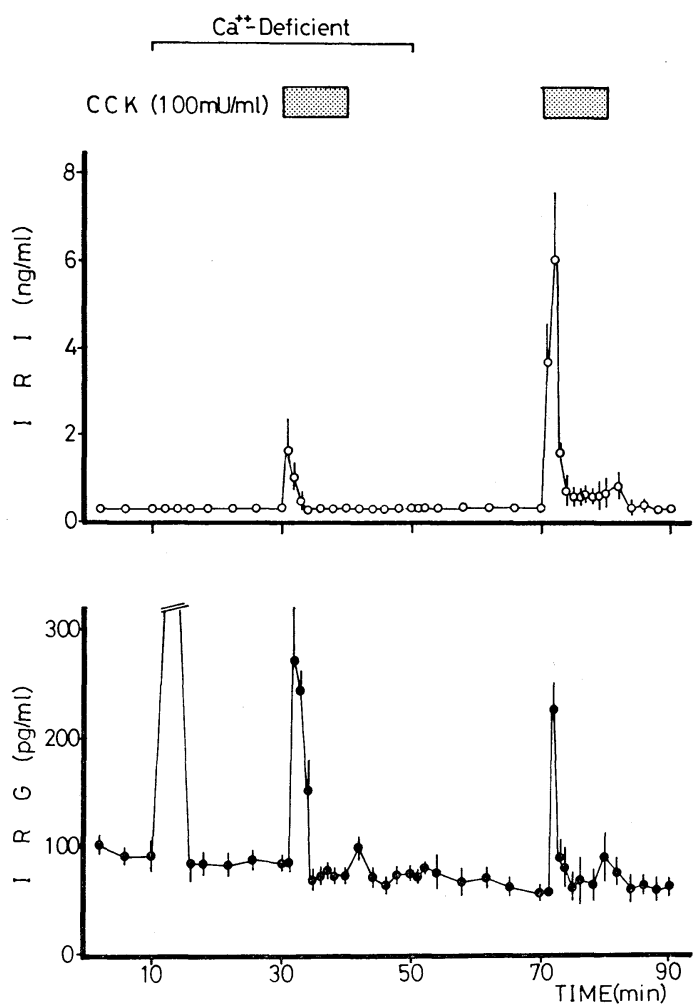

Fig. 4. Effect of calcium deprivation on IRI and IRG release induced by $100 \mathrm{mU} / \mathrm{m} l \mathrm{CCK}$ in the presence of $50 \mathrm{mg} / \mathrm{d} l$ glucose. Results are expressed as mean \pm SEM of 6 experiments.

The Effect of Extracellular Calcium Depletion on CCK-and Caerulein-Induced Insulin and Glucagon Release

In a calcium deprivation study, pancreases were perfused with a calcium-free medium for $20 \mathrm{~min}$ before, as well as during and $20 \mathrm{~min}$ after stimulation with $\mathrm{CCK}$ or caerulein. After a 40-min perfusion with calcium-free medium, the perfusion medium was changed to a calcium containing basic medium $(\mathrm{Ca}$ $2.5 \mathrm{~mm}$ ). From $20 \mathrm{~min}$ after the restoration of calcium, an infusion of CCK or caerulein at the same concentration as that in the absence of calcium was again administered for $10 \mathrm{~min}$.

In the absence of calcium, IRI release in response to $100 \mathrm{mU} / \mathrm{m} l \mathrm{CCK}$ was mar- 

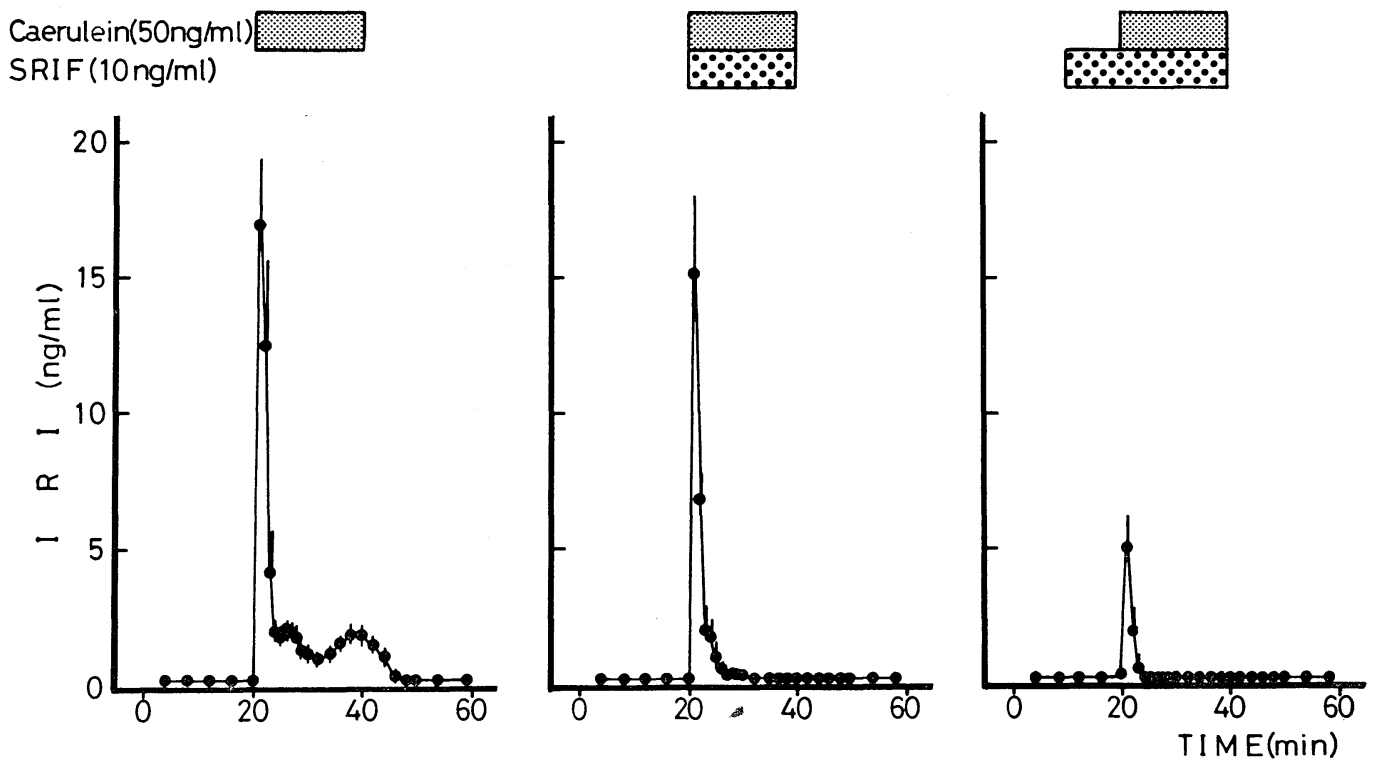

Fig. 5. Effect of somatostatin(SRIF) $(10 \mathrm{ng} / \mathrm{m} l)$ on caerulein $(50 \mathrm{ng} / \mathrm{m} l)$ induced IRI release from the isolated perfused rat pancreas. The caerulein stimulus was applied between 20 and 40 min. Left: Control experiment without SRIF infusion. Center: SRIF was added simultaneously with caerulein. Right: SRIF was applied $10 \mathrm{~min}$ prior to and during thecae rulein stimulation. Results are expressed as mean \pm SEM of 8 experiments.

kedly inhibited (Fig. 4, upper panel). However, an addition of a similar dose of CCK to the same preparation of perfused rat pancreas $20 \mathrm{~min}$ after the restoration of calcium resulted in IRI release similar in magnitude and pattern to control experiments (Fig. 1, upper panel). The peak value for IRI in response to $100 \mathrm{mU} / \mathrm{ml}$ and that in the presence of calcium was $1.5 \pm 0.6 \mathrm{ng} / \mathrm{m} l$ and those in the presence of calcium was $6.0 \pm 1.6 \mathrm{ng} / \mathrm{m} l$.

The output of IRG recorded in the absence of calcium (Fig. 4, lower panel) was comparable to that seen in the control experiment performed in the presence of calcium (Fig. 1, lower panel), but somewhat greater than that obtained in response to the second stimulation with the same peptide of the same preparation of the pancreas after calcium restoration (Fig. 4, lower panel).
The Effect of Somatostatin on CCK-and Caerulein-Induced Insulin and Glucagon Release

To examine the effect of SRIF on CCKand caerulein-induced IRI and IRG release, $10 \mathrm{ng} / \mathrm{m} l$ SRIF was added simulaneously or infused $10 \mathrm{~min}$ prior to and then during the infusion of the stimulating agent.

The addition of SRIF simultaneously with $50 \mathrm{ng} / \mathrm{m} l$ caerulein completely blocked the late phase of caerulein-induced IRI release. In contrast, the early secretory phase was not reduced (Fig. 5, center, Fig, 6 left). When SPIF was infused 10 min prior to and during the infusion of caerulein, both the early and the late phases of IRI release were markedly suppressed (Fig. 5, right). On the other hand, both, acute and late releases of IRG were almost completely blocked by concurrently administered SRIF (Fig. 6, right). 

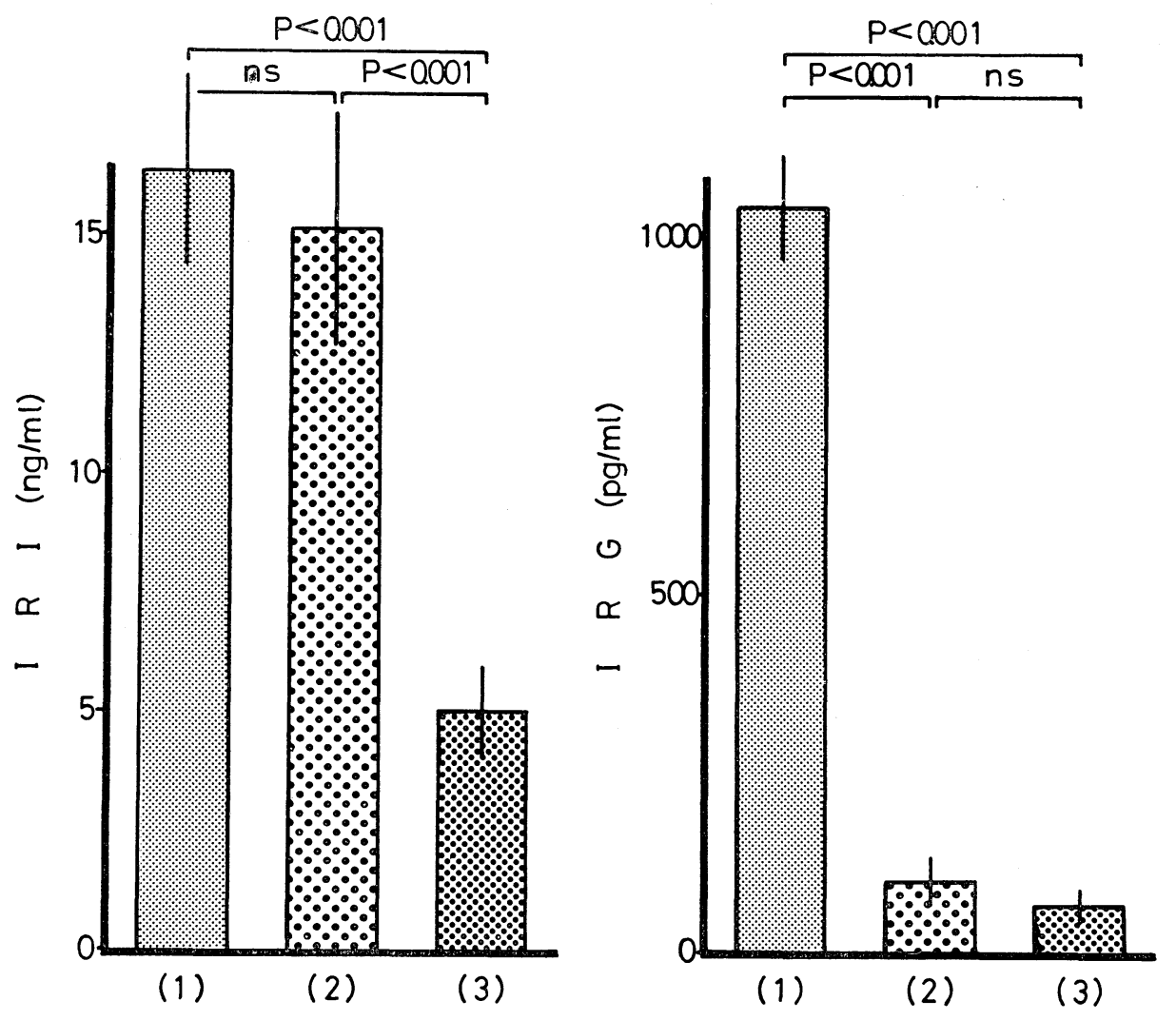

Fig. 6. Effect of SRIF on the maximal IRI and IRG concentration in the pancreatic effluent in response to $50 \mathrm{ng} / \mathrm{ml}$ caerulein. (1) control experiment without SRIF infusion, (2) SRIF was added simultaneously with caerulein, (3) SRIF was applied $10 \mathrm{~min}$ prior to and during the caerulein stimulation. Results are expressed as mean \pm SEM of 8 experiments.

Comparable results were obtained when $\mathrm{CCK}$ instead of caerulein was used to stimulate the endocrine pancreas in the presence of SRIF.

\section{Discussion}

These studies demonstrate that depletion of extracellular calcium markedly diminishes IRI response to CCK and caerulein but not IRG response. The addition of calcium to the calcium-depleted pancreas restored the ability of the beta-cell to secrete IRI. Therefore, calcium appears to be an essential requirement for the $\mathrm{CCK}$ - or caeruleininduced secretory process of IRI. On the other hand, calcinm depletion of the perfusate at a glucose concentration of $50 \mathrm{mg} / \mathrm{d} l$ did not, have any effect on CCK- or caruleininduced IRG release, though Gerich et al. (1974) and Leclercq-Mayer et al. (1978, 1979) have reported that a sufficient influx of calcium was required for IRG release to be stimulated by arginine. Since a lack of dependence on extracellular calcium was observed for IRG release, this calcium requirement for $\mathrm{CCK}$ - or caerulein-stimulated endocrine pancreatic function seems to be specific for IRI release. 
The findings of the present study suggest that inward calcium transport is not invariably required for the control of the secretory process in the alpha cell, though previous reports (Curry et al., 1968; Gerich et al., 1974; Grodsky and Bennett, 1966; Leclercq-eyer et al., 1973, 1976, 1978, 1979) have shown that calcium is essential for IRG secretion. Although it may be possible that IRG release has occurred because of incomplete depletion of tissue calcium, concomitant IRI release was significantly impaired in the system employed. Thus, it seemed likely that there was a significant depletion of tissue calcium. Therefore, the present results may indicate a differential sensitivity of CCK-and caerulein-stimulated alpha and beta cell to calcium depletion.

The present observations confirm the previous reports that SRIF is a potent inhibitor of IRG as well as IRI secretion in isolated perfused rat pancreas and demonstrates that inhibition of IRG secretion is greater and more striking than that of IRI (Bhathena et al., 1976; Gerich et al., 1974, 1975). SRIF had no effect on the acute release of IRI in response to $\mathrm{CCK}$ or caerulein given simultaneously, but significantly inhibited IRI release when SRIF was infused $10 \mathrm{~min}$ prior to and then during the infusion of the peptide. SRIF is a more effective inhibitor of IRG than of IRI release from the perfused rat pancreas in response to CCK or caerulein. The lesser effect of SRIF in blocking the acute phase of IRI secretion could be due to several mechanism. Contrary to the observations of Pek et al., (1976) who have demonstrated the release of IRG antecedent to that of IRI in response to a variety of stimuli common to both hormones, the present data suggest that with the administration of CCK or caerulein the secretory response of the beta cell consistently occurs faster than that of the alpha cell. Thus, unlike IRG secretion, which is completely inhibited by concurrently administered SRIF, pancreatic beta cells respond faster to $\mathrm{CCK}$ or caerulin stimulation and slower to SRIF inhibition. This explanation is consistent with the finding that pretreatment for $10 \mathrm{~min}$ with $10 \mathrm{ng} / \mathrm{ml}$ SRIF almost completely iuhibits IRI secretion.

Though several theories on the action of SRIF have been reported, the exact mechanism of its action is still unknown. As it has been recently shown that SRIF acts through the binding of calcium (Curry and Bennett ; 1974) or that SRIF acts on the islets of Langerhaus to impair calcium uptake (Bhathena et al., 1976), the effect of SRIF on hormonal discharge is suggested to be related to an alteration in the handling of or response to calcium (Bhathena et al., 1976; Curry and Bennett, 1974; Devis et al., 1977; Fujimoto and Ensinck, 1976).

The present studies demonstrate the difference in the calcium requirement for IRI and IRG release stimulated by CCK or caerulein. Contrary to previous observations, our results have shown that extracellular calcium is essential for IRI release but not for IRG release. While SRIF is an effective inhibitor of CCK- or caerulein-induced IRG release but not IRI secretion. The explanation for the difference of IRI and IRG response to CCK or caerulein in the absence of extracelluar calcium and in the presence of SRIF is unclear. Further investigation is needed to clarify the mechanism.

\section{References}

Auilar-Parada, E., E. M. Eisentraut and R. H. Unger (1969). Am. J. Med. Sci. 257, 415.

Bertaccini, G., G. de Caro, R. Endean, V. Erspamer and M. Impicciatore (1968). Br. J. Pharmacol. 34, 291.

Bertaccini, G., G. de Caro, R. Endean, V. Erspamer and M. Impicciatore (1969). ibid. 37, 185.

Bhathena, S. J., P. V. Perrino, N. R. Voyles, S. S. Smith, S. D. Wilkins, D. H. Coy, A. V. Schally and L. Recant (1976). Diabetes 25, 1031.

Buchanan, K. D., J. E. Vance, A. Morgan and R. H. Williams (1968). Am. J. Physiol. 215, 1293. 
Curry, D. L., L. L. Bennett and G. M. Grodsky (1968). ibid. 214, 174.

Desbuquois, B. and G. O. Auerbach (1971). J. Clin. Endocrinol. Metab. 33, 732.

Dupre J., J. D. Curtis, R. H. Unger, R. W. Wadell and J. C. Beck (1969). J. Clin. Invest. 48, 745.

Dupre, J., S. A. Ross, D. Watson and J. C. Brown (1973). J. Clin. Endocrinol. Metab. 37, 826.

Fujimoto, W. Y. and J. W. Ensinck (1976). Endocrinology 98, 259.

Gardner, J. D., T. P. Conlon, H. L. Klaeveman, T. D. Adams and M. A. Ondetti (1975). J. Clin. Invest. $56,366$.

Gerich, J. E., B. J. Frankel, R. Fansko, L. West, P. H. Forsham and G. M. Grodsky (1974). Endocrinology 94, 1381.

Gerich, J. E., R. Lovinger and G. M. Grodsky (1975). ibid. 96, 749 .

Grodsky, G. M. and L. L. Bennett (1966). Diabetes $15,910$.

Harper, A. A. and H. S. Raper (1943). J. Physiol. (Lond.). 102, 115.

Ipp, E., R. E. Dobbs, A. Arimura, W. Vale, V. Harris and R. H. Unger (1977). J. Clin. Invest. $60,760$.

Iversen, J. (1971). ibid. 50, 2123.

Iversen, J. and K. Hermansen (1977). Diabetologia $13,297$.

Ivy, A. C. and E. Oldberg (1928). Am. J. Physiol. $86,599$.
Kanno, T. and O. Nishimura (1976). J. Physiol. (Lond.). 257, 308.

Kanno, T., T. Suga and M. Yamamoto (1976). Jpn. J. Physiol. 26, 101.

Kanno, T. and M. Yamamoto (1977). J. Physiol. (Lond.). 264, 787.

Leclercq-Meyer, V., J. Marchand and W. J. Malaisse (1973). Endocrinology 93, 1360.

Leclercq-Meyer, V., J. Marchand and W. J. Malaisse (1976). Diabetologia 12, 531.

Leclercq-Meyer, V., J. Marchand and W. J. Malaisse (1978). Diabetes 27, 996.

Leclercq-Meyer, V., J. Marchand and W. J. Malaisse (1979). Am. J. Physiol. 236, E98.

Meade, R. C., H. A. Kneubuhler, W. J. Schulte and J. J. Borboiak (1967). Diabetes 16, 141.

Milner, R. D. G. and C. N. Hales (1967). Diabetologia $3,47$.

Otsuki, M., C. Sakamoto, H. Yuu, M. Maeda, S. Morita, A. Ohki, N. Kobayashi, K. Terashi, K. Okano and S. Baba (1979). J. Clin. Invest. 63, 478.

Pederson, R. A. and J. C. Brown (1976). Endocrinology 99, 780.

Pederson, R. A. and J. C. Brown (1978). 103, 610.

Pek, S., T.-Y. Tai, C. Crowther and S. S. Fajans (1976). Diabetes 25, 764.

Ravinovitch, A. and J. Dupre (1974). ibid. 94, 1139.

Rubin, R. D. (1970). Pharmacol. Rev. 22, 389.

Unger, R. H., H. Ketterer, J. Dupre and M. Eisentraut (1967). J. Clin. Invest. 46, 630. 